\title{
Encapsulated Neuroma on Glans Penis: A Case Report and Review of the Literature
}

\author{
Miguel Angel Rodriguez Cabello a , Jose Emilio Hernandez Sanchez ${ }^{\mathrm{b}, \mathrm{d}}$, \\ Ana Maria Gutierrez Pecharroman ${ }^{\mathrm{c}}$, Constantino Varona Crespo ${ }^{\mathrm{c}}$, \\ Francisco Javier Burgos Revilla ${ }^{\mathrm{a}}$
}

\begin{abstract}
One case of palisaded encapsulated neuroma on glans is reported. Palisaded encapsulated neuroma is a benign neural tumor whose location on glans is outstanding. It represents a separate clinicopathological entity. The characteristics of the neoplasm are reported and discussed.
\end{abstract}

Keywords: Neuroma alone; Benign neoplasm; Skin neoplasm

\section{Introduction}

This uncommon skin neoplasm of nervous origin was first described by Reed et al with the name "palisaded encapsulated neuroma" [1], but only recently has been recognized as a variety of tumor of peripheral nerve sheath [2]. It is a well-established clinicopathological entity. Its location is predominantly dermal, skin and facial. It rarely occurs in mucous membranes, and very exceptionally on glans. None described association with traumatic events or with syndromes such as MEN II, Gorlin syndrome, or neurofibromatosis type I. This is the fourth case reported in the literature of palisaded encapsulated neuroma on glans penis.

\section{Case Report}

A 61-year-old man with painless lesion on glans was referred

\footnotetext{
Manuscript accepted for publication March 11, 2014

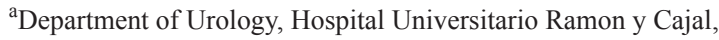
Madrid, Spain

${ }^{\mathrm{b}}$ Department of Urology, Complejo Asistencial de Avila, Avila, Spain

${ }^{\mathrm{c}}$ Department of Pathology, Hospital Universitario Ramon y Cajal, Madrid, Spain

${ }^{\mathrm{d}}$ Corresponding author: Jose Emilio Hernandez Sanchez, Department of Urology, Complejo Asistencial de Avila, Avenida de Juan Carlos I S/N, 05071-Avila, Spain. Email: dr_emilio_hernandez@hotmail.com

doi: http://dx.doi.org/10.14740/jmc1748w
}

to our hospital. The patient had no urological, dermatological or traumatic previous events. Grossly it was a unique papular lesion, approximately $1 \mathrm{~cm}$, smooth, reddish purple color, soft and shiny touch. The lesion had remained unchanged since its appearance for years. Excision of the lesion was performed under local anesthesia, and sent for pathologic e -xamination. The postoperative course was uneventful.

Microscopic examination revealed a well-defined nodular lesion, encapsulated, localized to subepithelial level, and composed of elongated spindle cell nuclei, occasionally wavy and fine tips, with little eosinophilic cytoplasm not clearly discernible (Fig. 1). These cells were arranged in short fascicles, often intersecting and forming occasional fences without Antoni type B, atypia or mitosis areas. Thickening shaped fibrous pseudocapsule surrounding the lesion was observed. Peripherally to the primary lesion frequently no pathologic peripheral nerve fascicles were described. Immunohistochemistry showed intense immunoreaction of spindle cells to anti-protein S-100 antibodies (Fig. 2). The presence of many axons crossing the lesion in close contact with Schwann cells was verified by staining with neurofilament (Fig. 3A). Likewise positivity with anti-epithelial membrane antigen in perineural cells from pseudocapsular area was evidenced in the form of fibrillar staining (Fig. 3B).

Patient did not need adjuvant treatment. One year after the patient had no tumor recurrence or functional sequelae.

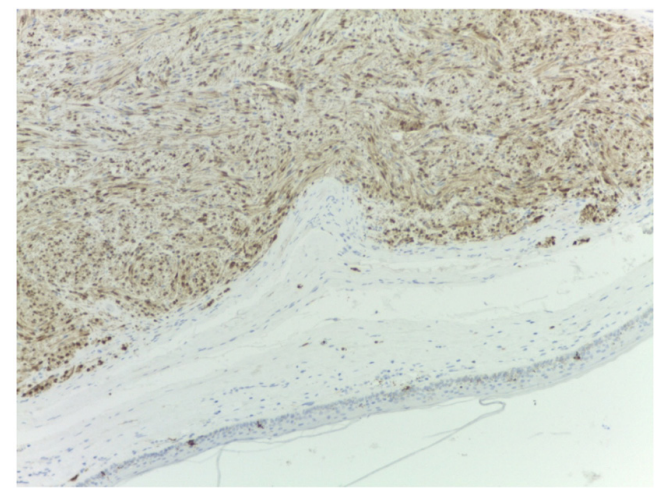

Figure 1. Hematoxylin-eosin staining. Pseudoencapsulated injury. 


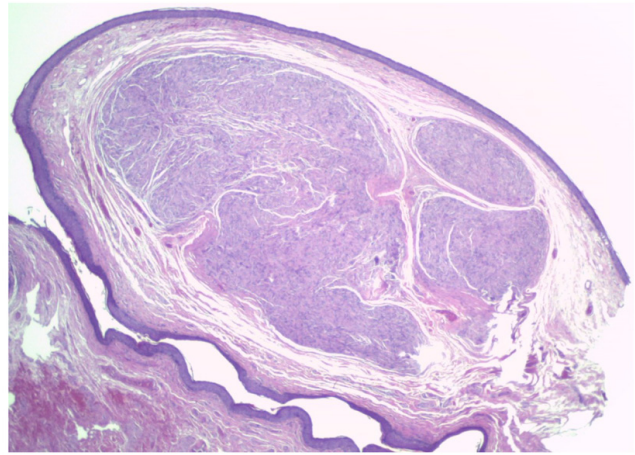

Figure 2. Immunohistochemistry with anti-protein S-100.

\section{Discussion}

The solitary circumscribed neuroma or "palisaded encapsulated neuroma" is a benign and relatively common neural tumor. This type of tumor occurs without clear predominance of sex, more common in adults between 30 and 50 years, and mostly on the face. Other sites have been described including mucous membranes. Its location on glans is extremely rare. This is the fourth case reported in the literature [3-5].

It usually occurs as a single papule, unpigmented, asymptomatic, and with a diameter close to $5 \mathrm{~mm}$. Its appearance suggests an important differential diagnosis with other lesions such as intradermal nevus, epidermal cyst, basal cell carcinoma and adnexal tumor [5].

It belongs to the peripheral nerve tumors group, either nerve sheath or other related structures [6, 7]. Electron microscopic examination identifies Schwann cells, perineural cells, fibroblasts and intratumoral axons. The tumor does not have a true capsule, but each tumor nest is bounded by a structure that is similar to the perineurium histologically and immunohistochemically [8].

These findings suggest a more complex source and differentiation; otherwise they would be only from Schwann cells of the nerve sheath [6]. Therefore, this group is referred to as peripheral neuroectodermal tumors. Differential diagnosis includes traumatic neuroma, solitary and plexiform schwannoma, solitary and plexiform neurofibroma, angioleiomyoma and plexiform fibrohistiocitoma [6].

It is important identification and differentiation from the most common varieties of peripheral nerve tumors. Although histologically similar to those of multiple mucosal neuromas syndrome, unlike them it is solitary, only skin and not associated with endocrine disorders of MEN type IIb syndrome [6, $9,10]$. Neither has been described in association with Von Recklinghausen's disease or other phakomatoses [10].

Although the nature of these tumors is not clarified, they are considered benign, spontaneously occurring and slowly developing. Its treatment is usually limited to local excision and adjuvant treatment is unnecessary [4].
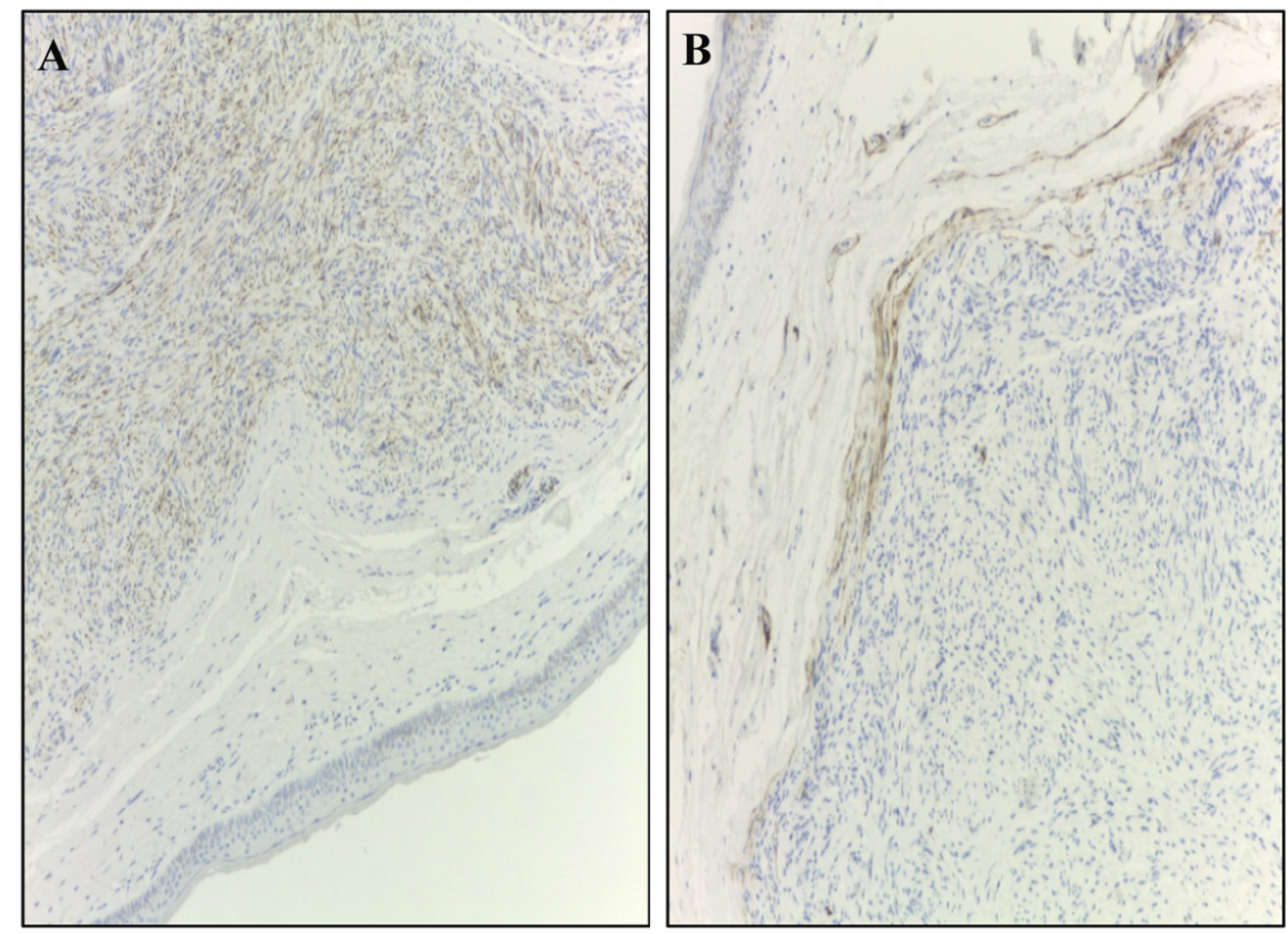

Figure 3. (A) Immunohistochemistry against neurofilament staining. (B) Immunohistochemistry with anti-epithelial membrane antigen (EMA). 
Table 1. Immunohistochemical Findings of Palisaded Encapsulated Neuroma

\begin{tabular}{lllll}
\hline & S-100 & NEUROFILAMENTS & NF & EMA \\
\hline Cells & + & + & + & - \\
Capsule & - & - & - & + \\
Stroma & - & - & - & - \\
\hline
\end{tabular}

\section{Conflict of Interest}

All authors declare no conflict of interest.

\section{References}

1. Reed RJ, Fine RM, Meltzer HD. Palisaded, encapsulated neuromas of the skin. Arch Dermatol. 1972;106(6):865870.

2. Argenyi ZB. Recent developments in cutaneous neural neoplasms. J Cutan Pathol. 1993;20(2):97-108.

3. Val-Bernal JF, Alvarez-Canas C, Vega A. Palisaded encapsulated neuroma of the glans penis. Urology. 1995;45(4):689-691.

4. Navarro M, Vilata J, Requena C, Aliaga A. Palisaded encapsulated neuroma (solitary circumscribed neuroma) of the glans penis. Br J Dermatol. 2000;142(5):1061-1062.

5. Javier Ibarra de la Rosa, Alex Llambrich Manes, Fer- nando Terrasa Sagrista. Neuroma solitario circunscrito (neuroma encapsulado en empalizada) de glande. ISBN: 978-84-692-76778.

6. Requena L, Sangueza OP. Benign neoplasms with neural differentiation: a review. Am J Dermatopathol. 1995; 17(1):75-96.

7. Fletcher CD. Solitary circumscribed neuroma of the skin (so-called palisaded, encapsulated neuroma). A clinicopathologic and immunohistochemical study. Am J Surg Pathol. 1989;13(7):574-580.

8. Gonzalez S, Segobia L, Andrade L. Neuroma solitario de la piel. Descriccion de 11 casos. Actas Dermosifiliogr. 1990;90:389-393.

9. Gorlin RJ, Sedano HO, Vickers RA, Cervenka J. Multiple mucosal neuromas, pheochromocytoma and medullary carcinoma of the thyroid--a syndrome. Cancer. 1968;22(2):293-299 passim.

10. Williams ED, Pollock DJ. Multiple mucosal neuromata with endocrine tumours: a syndrome allied to von Recklinghausen's disease. J Pathol Bacteriol. 1966;91(1):7180. 